\title{
ELECTROMAGNETIC RADIATION EXPOSURE FROM CELLULAR BASE STATION: A CONCERN FOR PUBLIC HEALTH
}

\author{
A. Ozovehe ${ }^{1, *}$, A. U. Usman ${ }^{2}$ and A. Hamdallah ${ }^{3}$ \\ 1 Trifield TEChNology Limited, 14 ISHAQ MaAjI CRESCENT,GWAGWALADA ABUJA, NIGERIA \\ 2 DEPARTMENT OF ELECTRICAL/ELECTRONIC ENGINEERING, FEDERAL UNIVERSITY OF TECHNOLOGY, MinNA, NiGERIA \\ ${ }^{3}$ DEPARTMENT OF SCIENCE AND ENVIRONMENTAL EDUCATION, UNIVERSITY OF ABUJA UNIVERSITY, NIGERIA \\ E-mail addresses:1 aliyu123oz@gmail.com,2 abrausman@yahoo.com 3 hamdallah123oz@gmail.com
}

\begin{abstract}
For cellular network Base Transceiver Station (BTS) antennas to operate as intended without adverse health effects, they must comply with Electromagnetic Compatibility (EMC) standards as well as safety guidelines relating to exposure of non-ionizing radiation. Global System for Mobile Communication (GSM) operators claimed that their equipment comply with international standards and thus the radiated field propagated from their installation complies with International Commission on Non-Ionizing Radiation Protection (ICNIRP) requirements. However, the installation of GSM BTS might not comply with maximum exposure limit as Nigeria Communication Commission (NCC) does not supervise the installation, therefore, the public and more specifically, the maintenance personnel's health might be at risk. More worrisome is that investigation has shown that none of the cellular network operators in Nigeria provide quality training for their worker on awareness of occupational radiation hazards from BTS. This paper call for caution and show how best practice can be followed by general public and maintenance personnel to avoid being exposed to radiation so that their health is not at risk while the uncertainties about the hazard effects last.
\end{abstract}

Keywords: EMC, EMI, EMS, Public health, specific absorption rate

\section{INTRODUCTION}

According to Maxwell's equation, all electrical/ electronic apparatus radiate electromagnetic energy during their normal operation because of displacement current that is associated with movement of charges that is responsible for the electric current. The electromagnetic energy (the power density of the radiation measured in $\mathrm{W} / \mathrm{m}^{2}$ ) can interfere with normal operation of living organisms in the same electromagnetic environment, and thereby adversely affecting their performance. For electromagnetic interference to exist there must be a noise source, a path, and a victim to enable the transfer of energy from the source to the victim. Victim is any system whose functional operation is affected by such interference [1].

Electromagnetic Compatibility (EMC) exists when the noise generated by electrical/electronic devices does not interfere with the normal operation of living organisms in the same electromagnetic environment. Such living organisms are said to be electromagnetic compatible. EMC ensures effective control of both unintentional and intentional emissions from interfering with operation of living organisms [2]. The subject of EMC can be divided into three aspects as follows, and as shown in Figure 1 [3].

Electromagnetic interference (EMI) which is defined as undesirable electromagnetic signal from a device that inhibits proper working of a living organism. Electromagnetic susceptibility (EMS) which is referred to as the degree of degradation suffered by a living organism's performance as a result of electromagnetic interference.

The coupling path between emission and susceptibility accounts for radiated electromagnetic field in the far field; magnetic and electric field in near radiating field and conducted energy (electric current) in non-radiating near field. Studies of possible hazards to human health from exposure to radio frequency (RF) electromagnetic fields show that there is need for control of exposure to radiation [4]. Exposure to $\mathrm{RF}$ radiation in excess of power density of $50 \mathrm{~W} / \mathrm{m}^{2}$ for 
occupational exposure or $10 \mathrm{~W} / \mathrm{m}^{2}$ for general public exposure given in ICNIRP basic restriction, may cause adverse health effects such as blood brain barrier, cancer and sleep effects $[5,6]$. The type and extent of the effects depends on the strength of the field, the exposure duration, and on various other factors such as the frequency, type of modulation, polarization, and distance from the source $[7,8]$.

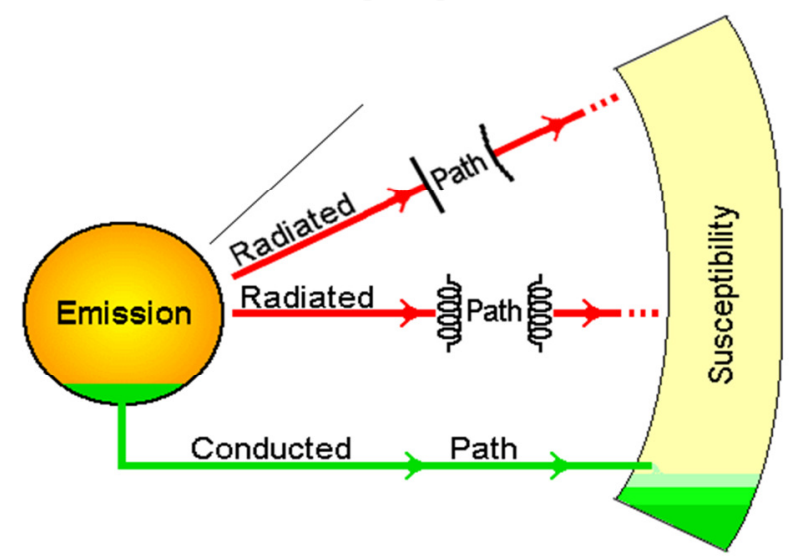

Fig. 1: Three components of Displacement Current

This work thus provides basic guidance on working conditions and procedures that will lead to higher standards of safety for all personnel engaged in the operation and maintenance of base stations as well as the entire public in order to observed basic restrictions set by ICNIRP as shown in Table 1 [20].

Table 1: Basic restrictions between 10 and $300 \mathrm{GHz}$

\begin{tabular}{cc}
\hline Exposure characteristics & Power density $\left(\mathrm{W} / \mathrm{m}^{2}\right)$ \\
\hline Occupational exposure & 50 \\
General public & 10 \\
\hline
\end{tabular}

\section{GENERAL HEALTH HAZARDS OF BASE STATION EMISSIONS}

One strong area of concern in mobile communication is the radiation emitted by the fixed infrastructure used in mobile telephony, such as base stations and their antennas, which provide the link to and from mobile phones. This, in contrast to mobile handsets radiation is emitted continuously and is more powerful at close range. On the other hand, field intensities drop rapidly with distance away from the base of the antenna because of the attenuation of power with the square of distance. Several surveys have identified increases of certain health related symptoms depending upon proximity to electromagnetic sources such as mobile phone base stations [8].
A 2003 survey study by [9] in France found a variety of self-reported symptoms such as fatigue, headache, sleep disruption and loss of memory for people who reported that they were living within $300 \mathrm{~m}$ of GSM cell towers in rural areas, or within $100 \mathrm{~m}$ of base stations in urban areas. Similar results have been obtained with GSM cell towers in Spain, Egypt, Poland and Austria.

On the contrary, a study conducted at the University of Essex and another in Switzerland concluded that mobile phone masts were unlikely to be causing these short term effects in a group of volunteers who complained of such symptoms [10]. The Essex study however has been criticized as being skewed due to drop-outs of test [11].

\section{MEASUREMENT AND EVALUATION}

Exposure limits to electromagnetic radiation is usually defined in terms of specific absorption rate (SAR) because it is closely related to biological impact. To simplify compliance testing, these biologically effective quantities are converted into external field levels and power densities. The external fields are free electric field and magnetic field strength which can easily be measured in real-life exposure [12]. Therefore, international and national standards provide exposure limits in terms of power density $S$ $\left(\mathrm{W} / \mathrm{m}^{2}\right)$ or in terms of electric field strength $E(\mathrm{~V} / \mathrm{m})$ and magnetic field strength $H(\mathrm{~A} / \mathrm{m})$. At far-field where the radiation becomes a plane wave, power density can be evaluated from field strengths and the relationship between power density and electric field strength as described by equation (1). However, this equation does not hold for the near-field - where the relationship between the fields is no longer linear. Hence, $E$ and $H$ are determined independently.

$$
\mathrm{E}(\mathrm{V} / \mathrm{m})=\sqrt{\mathrm{S}\left(\mathrm{W} / \mathrm{m}^{2}\right) \times 377(\Omega)}
$$

E and $H$ can be determined practically at about $10 \mathrm{~m}$ from the base station, and the measurement of the electric field strength is sufficient to get other limits. The limits are frequency dependent as shown in Figures 2 and 3 for ICNIRP, 2009 limits [13]. Since electromagnetic field is frequency dependent, exposure limits must also be frequency dependent. To evaluate the contribution by the radio frequency field exposure from base station antennae, frequencyselective measurement must be employed [13].

The second method for specific absorption rate (SAR) determination is to measure the electric field inside 
the body with implantable electric field probes and then calculate the $S A R$ as shown in equation (2)

$$
\mathrm{SAR}=\sigma \mathrm{E}^{2} / \rho
$$

where $\sigma$ is the tissue conductivity $(\mathrm{S} / \mathrm{m}), E$ is the electric field strength induced in the tissue $(\mathrm{V} / \mathrm{m})$ and $\rho$ is the mass density $(\mathrm{kg} / \mathrm{m} 3)$.

This method is suitable only for measuring $S A R$ at specific points in the body and for low values of $S A R$ where the absorbed energy is insufficient to cause a detectable change in temperature. Instrumentation for this type of $S A R$ measurement method usually includes an implantable electric field probe, a phantom and a computer controlled system for positioning the probe [14 and 15].

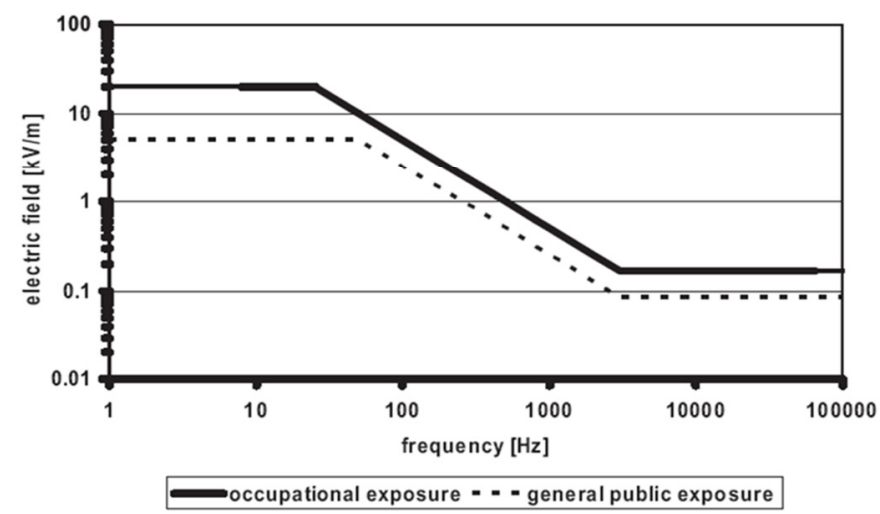

Figure 2: Frequency-dependent electric field

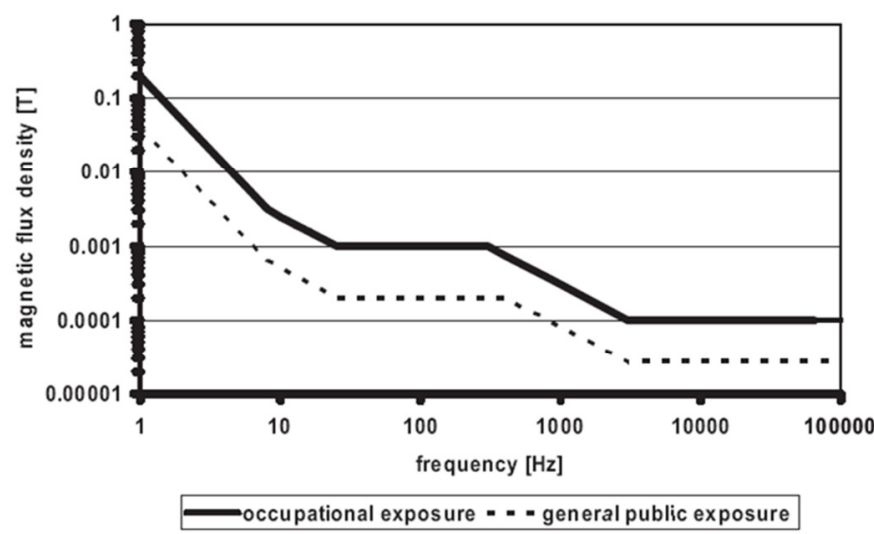

Figure 3: Frequency-dependent magnetic flux density

The electromagnetic fields exposure levels can be characterized by the power density at a distance of about $10 \mathrm{~m}$ from GSM BTS antennae [16, 21].

\section{CONFORMITY IN NIGERIA}

Although the work of [17 and 18] carried out in Lagos on cellular networks, suggests that there is basically no health risk in areas accessible to the public around the BTSs in Nigeria as far as conformity to ICNIRP, 2009 safety limit is concerned, the risk associated with the maintenance personnel needs to be further investigated. Even with that, the result of their measurement is only true for the configuration and the environment where the measurement were carried out and will continue to be so only if the output power of BTSs transmitters are not increased and their positions on the towers remain-unchanged. It is however to be noted that the situation may be considerably different when the number of installed GSM and Fixed wireless BTSs increase significantly beyond number at the time of the study. Hence, the need for such measurements to be frequently repeated, say twice in a year so that operators will be at alert to operate according to standard recommendations for the safety of all.

\section{RECOMMENDATIONS}

The European Council Recommendation on the limitation of exposure of the general public to electromagnetic fields $(1 \mathrm{~Hz}-300 \mathrm{GHz})$ has recommended that Member States should aim to achieve restrictions for public exposure based on ICNIRP, 2009 [21]. It also mandated them to provide information on exposure to electromagnetic fields to the public. Therefore, Nigerian Communication Commission (NCC) needs to launch the same campaign in Nigeria and develop data bank for RF radiation from different network providers for risk management and higher standards of safety for all.

\section{CONCLUSION}

There is need to carry out practical measurements around the BTSs in Nigeria in order to determine whether the radiations comply with standards and to assess the risk they pose to the people, particularly the young and elderly .

\section{REFERENCES}

[1] Ade Ogunsola, "'The Need for Standardization and Regulation on Electromagnetic Compatibility in Africa", Proceeding of National Conference and Exhibition on Telecommunications and Broadcasting in Nigeria, 2006, Organised by Department of Electrical/Electronics Engineering, University of Lagos, Vol1,p64.

[2] Australian Communication Authority, "The electromagnetic compatibility frame work information for suppliers", http:// www.sma.gov .au/_vt_bin/sht.exe/emc/index.htm/map4. Accessed on 24 , October, 2005 .

[3] Williamson, "Electromagnetic Compatibility", webmaster@Williamson-labs.com 
[4] Hyland, G.J, "How Exposure to GSM and TETRA BaseStation Radiation can adversely affect Humans" Department of Physics, University of Warwick Coventry, UK.

[5] Salford, Leif G.; Arne E. Brun, Jacob L. Eberhardt, Lars Malmgren, and Bertil R. R. Persson, "Nerve Cell Damage in Mammalian Brain after Exposure to Microwaves from GSM Mobile Phones", Environmental Health Perspectives (United States: National Institute of Environmental Health Sciences) 111 (7): 881-883. doi:10.1289/ehp.6039. $\underline{\text { PMID } 12782486 .}$. $\underline{\text { PMC } 1241519}$ http://www.ehponline.org/members/2003/6039/6 039.html

[6] Borbély, AA; Huber R; Graf T; Fuchs B; Gallmann E; Achermann $P$, "Pulsed high-frequency electromagnetic field affects human sleep and sleep electroencephalogram". Neuroscience Letters (East Park, Ireland: Elsevier Science Ireland) 275 (3): 207-10. doi:10.1016/S0304-3940(99)00770-3. PMID 10580711.p 3.

[7] Stuchly M.A, "Proposed Revision of the Canadian Recommendations on Radiofrequency - Exposure Protection", Health Physics, Vol. 53, pp. 649-665, 1987.

[8] Stuchly M.A. and Xi, W, "Review of Current Literature on Biological Effects of Electromagnetic Fields in the Frequency Range $300 \mathrm{~Hz}$ to $300 \mathrm{GHz}$ ", A contract report submitted to Health Canada, October 1994 (Available at cost from the Radiation Protection Bureau, Health Canada, Ottawa,Ontario K1A 1C1).

[9] Santini, R; Santini, P; Danze, JM; LeRuz, P; Seigne, M, "Survey Study of People Living in the Vicinity of Cellular Phone Base Stations". Electromagnetic Biology and Medicine http://www.informaworld. com $/$ smpp/content $\sim$ content $=a 713628949$

[10] Eltiti, S; Wallace, D; Ridgewell, A; Zougkou, K; Russo, R; Sepulveda, F; Mirshekar-Syahkal, D; Rasor, P; Deeble, R; Fox, E, "Does short-term exposure to mobile phone base station signals increase symptoms in individuals who report sensitivity to electromagnetic fields A double-blind randomized provocation study". Environ Health Perspectives 115 (11).

[11] Randerson, James, "Research fails to detect shortterm harm from mobile phone masts". The Guardian (Guardian Media Group), http://www.guardian.co.uk/mobile/article/0,2134 778,00.html

[12] Wolfgang Mullner, "Precise Power Flux Density Measurement at Base Station" @ www.ce-mag.com

[13] ICNIRP, "Guide lines for limiting exposure level to time-varying electric, magnetic and electromagnetic fields" Health physic 2009.

[14] Balzano Q., Garay O. and Manning T. J, "Electromagnetic Energy Exposure of Simulated Users of Portable Cellular Telephones", IEEE Trans. Vehicular Tech., Vol. VT-44, pp. 390-403, 1995.

[15] Schmid T., Egger O. and Kuster N., "Automated EField Scanning System for Dosimetric Assessments", IEEE Trans. Microwave Theory Tech., Vol. 44, No. 1, pp. 105-113, 1996.

[16] Mann S. M, "Exposure to radio waves near mobile phone base stations", NRPB-R321, National Radiological Protection Board, Chilton, UK. June 2000.

[17] Aliyu .0, Adekola S. A. and Ade 0., "Practical Assessment of Exposure Levels due to Radiations from GSM Base Stations in Lagos", The $5^{\text {th }}$ International Conference on Power and Telecommunications, ICEPT-2009, Abuja, Nigeria, October 2009, p20

[18] Aliyu, O, Adekola S. A. and Ade O., "Design of C Antennae for Testing Electromagnetic Compatibility of GSM Equipment", The $5^{\text {th }}$ International Conference on Power and Telecommunications, ICEPT-2009, Abuja, Nigeria, October 2009, p20

[19] Michrowski Andrew, "Electromagnetic Pollution", Consumer Health and The Planetary Association for Clean Energy 1999, Inc. and ESSENTIA Communications Inc., 100 Bronson Avenue, \#1001, Ottawa, K1R 6G8, 613-238-4437,Volume 14, Issue3, March,1991

[20] ICNIRP "Guidelines for limiting exposure to timevarying electric, magnetic, and electromagnetic fields", Health Phys 1998

[21] Ulf Bergqvist, Gerd Friedrich, Yngve Hamnerius, Luc Martens, Georg Neubauer, György Thuroczy, Evi Vogel and Joe Wiart "Report of a Short Term Mission on Base Station Exposure to electromagnetic fields within COST 244bis", ftp://ftp.cordis.lu/pub/ ist/docs $/ \mathrm{ka} 4 / \mathrm{cost} 244$ base station emf.pdf. 